\title{
Wind interference effect on an octagonal plan shaped tall building due to square plan shaped tall buildings
}

\author{
Rony Kar $^{1} \cdot$ Sujit Kumar Dalui ${ }^{1}$
}

Received: 24 February 2015/Accepted: 7 February 2016/Published online: 20 February 2016

(C) The Author(s) 2016. This article is published with open access at Springerlink.com

\begin{abstract}
The variation of pressure at the faces of the octagonal plan shaped tall building due to interference of three square plan shaped tall building of same height is analysed by computational fluid dynamics module, namely ANSYS CFX for $0^{\circ}$ wind incidence angle only. All the buildings are closely spaced (distance between two buildings varies from $0.4 h$ to $2 h$, where $h$ is the height of the building). Different cases depending upon the various positions of the square plan shaped buildings are analysed and compared with the octagonal plan shaped building in isolated condition. The comparison is presented in the form of interference factors (IF) and IF contours. Abnormal pressure distribution is observed in some cases. Shielding and channelling effect on the octagonal plan shaped building due to the presence of the interfering buildings are also noted. In the interfering condition the pressure distribution at the faces of the octagonal plan shaped building is not predictable. As the distance between the principal octagonal plan shaped building and the third square plan shaped interfering building increases the behaviour of faces becomes more systematic. The coefficient of pressure $\left(C_{\mathrm{p}}\right)$ for each face of the octagonal plan shaped building in each interfering case can be easily found if we multiply the IF with the $C_{\mathrm{p}}$ in the isolated case.
\end{abstract}

Sujit Kumar Dalui

sujit_dalui@rediffmail.com

Rony Kar

ronykar123@gmail.com

1 Department of Civil Engineering, Indian Institute of Engineering Science and Technology, Shibpur, Howrah, India
Keywords Computational fluid dynamics - Interference effect · Tall building · Channelling effect - Shielding effect $\cdot$ Interference factor

\section{Introduction}

With the advent of latest analysis and design technology as well as high strength materials, the number of high-rise buildings is increasing. So wind engineering is getting more and more importance as the need for calculation of wind impact and interference of other structures on tall buildings arise. Wind engineering analyses the effects of wind in the natural and the built environment and studies the possible damage, inconvenience or benefits which may result from wind. In the field of structural engineering it includes strong winds, which may cause discomfort and damage, as well as extreme winds, such as in a cyclone, tornado, hurricane which may cause widespread destruction. Effect of wind on any structures is considered mainly in two directions: one is acting along the flow of wind which is called drag and the other is perpendicular to the wind flow which is called lift. Structures are subjected to aerodynamic forces which include both drag and lift. If the distance between centre of rigidity of the structure and the centre of the aerodynamic forces is large the structure is also subjected to torsional moments which may significantly affect the structural design. Interference effects due to wind are caused by the presence of adjacent structures, resulting in a change in wind loads on the principal building with respect to the isolated condition. The change mainly depends upon the shape, size and relative positions of these buildings as well as the wind incidence angle and upstream exposure. The main reasons for the lack of a comprehensive and generalized set of guidelines for wind 
load modifications caused by interference effects are as follows. There are a large number of variables involved including the height and plan shape and size of buildings, their distances from one another, wind incidence angles, topographical condition and different meteorological condition. There is a general misconception that the severity of wind loads on a building is less if surrounded by other structures than the isolated condition. Many works done earlier in the field of wind engineering include wind pressure characteristics, wind flow, dynamic response, interference effect etc. for tall structures as well as short structures. Cheng et al. (2002) performed aeroelastic model tests to study the across wind response and aerodynamic damping of isolated square-shaped high-rise buildings. Kim and You (2002) investigated the tapering effect for reducing wind-induced responses of a tapered tall building, by conducting high-frequency force-balance test. Lakshmanan et al. (2002) conducted pressure measurement studies on models of three structures with different plan shapes - a circular, an octagonal and an irregular shape under simulated open terrain conditions using the boundary layer wind tunnel. Thepmongkorna et al. (2002) investigated interference effects from neighbouring buildings on wind-induced coupled translational-torsional motion of tall buildings through a series of wind tunnel aeroelastic model tests. Tang and Kwok (2004) conducted a comprehensive wind tunnel test program to investigate interference excitation mechanisms on translational and torsional responses of an identical pair of tall buildings. Xie and Gu (2004) tried to find the mean interference effects between two and among three tall buildings studied by a series of wind tunnel tests. Both the shielding and channelling effects are discussed to understand the complexity of the multiplebuilding effects. Lam et al. (2008) investigated interference effects on a row of square-plan tall buildings arranged in close proximity with wind tunnel experiments. Agarwal et al. (2012) conducted a comprehensive wind tunnel test programme to investigate interference effects between two tall rectangular buildings. Tanaka et al. (2012) carried out a series of wind tunnel experiments to determine aerodynamic forces and wind pressures acting on square-plan tall building models with various configurations: corner cut, setbacks, helical and so on. The number of literatures on interference effect on tall buildings other than rectangular plan shape is quite low. Further the wind loading codes [(ASCE 7-10, IS-875 (Part 3) 1987, AS/NZS: 1170.2:2002, etc.] does not provide any guidelines for incorporating interference effect in structural design, which necessitates more research on this area. The current work mainly focuses on the wind-induced interference effect on an octagonal plan shaped tall building due to the presence of three square plan shaped building of same height for $0^{\circ}$ wind incidence angle.

\section{Numerical analysis of a tall building by CFD}

In the present study the octagonal plan shaped building in isolated as well as interference condition is analysed by the CFD package namely ANSYS CFX (version 14.5). The boundary layer wind profile is governed by the power law equation:

$U(z)=U_{\infty}\left(\frac{z}{z_{0}}\right)^{\alpha}$

A power law exponent of 0.133 is used which satisfies terrain category II as mentioned in IS 875-part III (1987).

\section{Details of model}

The buildings are modelled in 1:300 scale and the wind velocity scale is $1: 5$ (scaled down velocity $10 \mathrm{~m} / \mathrm{s}$ ). $K-\varepsilon$ model is used for the numerical simulation. The $k-\varepsilon$ models use the gradient diffusion hypothesis to relate the Reynolds stresses to the mean velocity gradients and the turbulent viscosity. The turbulent viscosity is modelled as the product of a turbulent velocity and turbulent length scale. $k$ is the turbulence kinetic energy and is defined as the variance of the fluctuations in velocity. It has dimensions of $\left(\mathrm{L}^{2} \mathrm{~T}^{-2}\right) . \varepsilon$ is the turbulence Eddy dissipation and has dimensions of per unit time. The continuity equation and momentum equations are:

$$
\begin{aligned}
& \frac{\partial \rho}{\partial t}+\frac{\partial}{\partial x j}(\rho U j)=0 \\
& \frac{\partial \rho U_{i}}{\partial t}+\frac{\partial}{\partial x_{j}}\left(\rho U_{i} U_{j}\right)=-\frac{\partial p^{\prime}}{\partial x_{i}}+\frac{\partial}{\partial x_{j}}\left[\mu_{\text {eff }}\left(\frac{\partial U_{i}}{\partial x_{j}}+\frac{\partial U_{j}}{\partial x_{i}}\right)\right]+S_{M}
\end{aligned}
$$

where $S_{M}$ is the sum of body forces, $\mu_{\mathrm{eff}}$ is the effective viscosity accounting for turbulence, and $p^{\prime}$ is the modified pressure. $\rho$ and $U$ denote density and velocity respectively. The $k-\varepsilon$ model is based on the eddy viscosity concept, so that

$\mu_{\text {eff }}=\mu+\mu_{\mathrm{t}}$

$\mu_{t}$ is the turbulence viscosity.

$\mu_{t}=C_{\mu} \rho \frac{k^{2}}{\varepsilon}$

The values of $k$ and $\varepsilon$ come directly from the differential transport equations for the turbulence kinetic energy and turbulence dissipation rate:

$$
\begin{aligned}
& \frac{\partial(\rho k)}{\partial t}+\frac{\partial}{\partial x_{j}}\left(\rho k U_{j}\right) \\
& =\frac{\partial}{\partial x_{j}}\left[\left(\mu+\frac{\mu_{t}}{\sigma_{k}}\right) \frac{\partial k}{\partial x_{j}}\right]+P_{k}+P_{\mathrm{b}}-\rho \varepsilon-Y_{M}+S_{k}
\end{aligned}
$$




$$
\begin{aligned}
\frac{\partial(\rho \varepsilon)}{\partial t}+\frac{\partial}{\partial x_{j}}\left(\rho \varepsilon U_{j}\right)= & \frac{\partial}{\partial x_{j}}\left[\left(\mu+\frac{\mu_{t}}{\sigma_{\varepsilon}}\right) \frac{\partial \varepsilon}{\partial x_{j}}\right]+\rho C_{1} S_{\varepsilon} \\
& -\rho C_{2} \frac{\varepsilon^{2}}{k+\sqrt{v \varepsilon}}+C_{1 \varepsilon} \frac{\varepsilon}{k} C_{3 \varepsilon} P_{\mathrm{b}}+S_{\varepsilon}
\end{aligned}
$$

$P_{\mathrm{k}}$ represents the generation of turbulence kinetic energy due to the mean velocity gradients, $P_{\mathrm{b}}$ is the generation of turbulence kinetic energy due to buoyancy and $Y_{m}$ represents the contribution of the fluctuating dilatation in compressible turbulence to the overall dissipation rate, $C_{1}$ and $C_{2}$ are constants. $\sigma_{k}$ and $\sigma_{\varepsilon}$ are the turbulent Prandtl numbers for $k$ (turbulence kinetic energy) and $\varepsilon$ (dissipation rate). The values considered for $C_{1 \varepsilon}, \sigma_{k}$ and $\sigma_{\varepsilon}$ are $1.44,1$ and 1.2 respectively.

\section{Domain and meshing}

A domain having $5 h$ upwind fetch, $15 h$ downwind fetch, $5 h$ top and side clearance, where $h$ is the height of the model as shown in Fig. 1 is constructed as per recommendation of Franke et al. (2004). Such a large domain is enough for generation of vortex on the leeward side and avoids backflow of wind. Moreover no blockage correction is required. Tetrahedral elements are used for meshing the domain. The mesh near the building is smaller compared to other location so as to accurately resolve the higher gradient region of the fluid flow. The mesh inflation is provided near the boundaries to avoid any unusual flow.

The velocity of wind at inlet is $10 \mathrm{~m} / \mathrm{s}$. No slip wall is considered for building faces and free slip wall for top and side faces of the domain. The relative pressure at outlet $0 \mathrm{~Pa}$. The operating pressure in the domain is considered as 1 atm, i.e. 101,325 $\mathrm{Pa}$. The Reynolds number of the model varies from $3.7 \times 10^{6}$ to $4.0 \times 10^{6}$.

\section{Validation}

Before starting the numerical analysis of the octagonal plan shaped building the validity of the ANSYS CFX package is checked. For this reason a square plan shaped building (Fig. 2) of dimension $100 \mathrm{~mm} \times 100 \mathrm{~mm}$ and height $500 \mathrm{~mm}$ (i.e. aspect ratio 1:5) is analysed in the aforementioned domain by $K-\boldsymbol{\varepsilon}$ model using ANSYS CFX under uniform wind flow.

Uniform wind flow of velocity $10 \mathrm{~m} / \mathrm{s}$ is provided at the inlet. The domain is constructed as per recommendation of Franke et al. (2004) as mentioned before. The face average values of coefficient of pressures are determined by ANSYS CFX package and compared with wind action codes from different countries.

From Table 1 it can be seen that result found by the package is approximately same with the face average value of

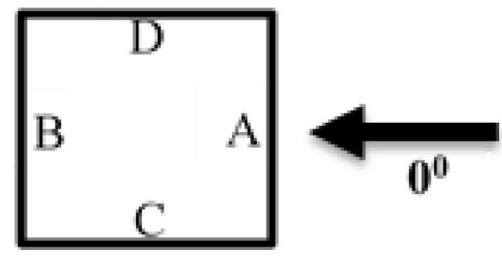

Fig. 2 Different faces of the model with direction of wind

Table 1 Comparison of face average values of coefficients of pressure

\begin{tabular}{lllll}
\hline Wind loading code & Face-A & Face-B & Face-C & Face-D \\
\hline By ANSYS CFX & 0.83 & -0.47 & -0.6 & -0.6 \\
ASCE 7-10 & 0.8 & -0.5 & -0.7 & -0.7 \\
AS/NZS-1170.2(2002) & 0.8 & -0.5 & -0.65 & -0.65 \\
IS: 875 (part 3) (1987) & 0.8 & -0.25 & -0.8 & -0.8 \\
\hline
\end{tabular}

Fig. 1 Computational domain for isolated building model used for CFD simulation

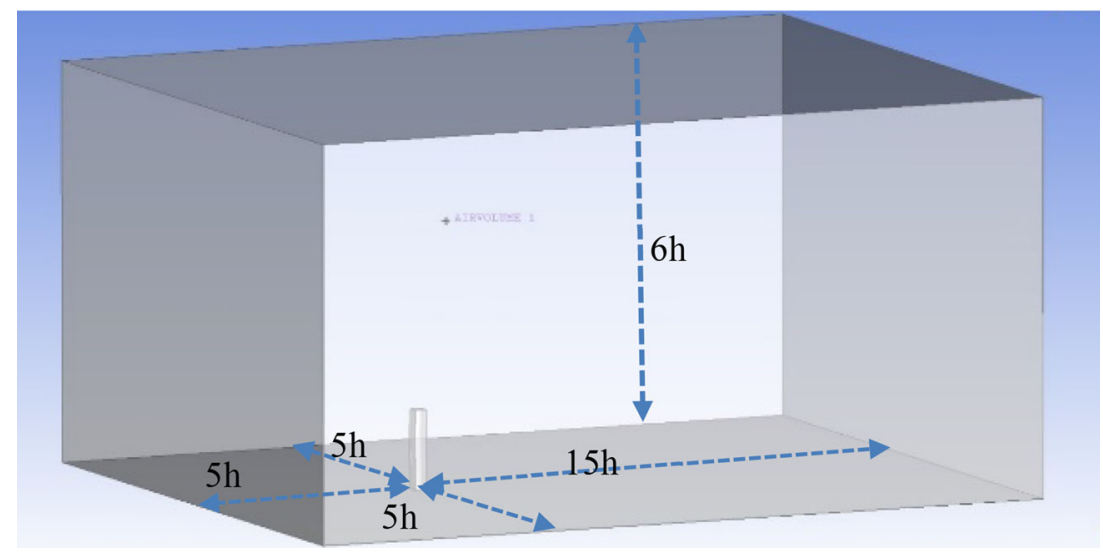


coefficient of pressure mentioned in AS/NZS-1170.2(2002). While there is difference in other codes it is due to different flow conditions and methods adopted.

\section{Parametric study}

The actual height of the building is $150 \mathrm{~m}$ and the diameter of the circle inscribed in the plan shape is $30 \mathrm{~m}$ for both the principal octagonal plan shaped building and square plan shaped interfering buildings. The buildings are modelled in 1:300 scale. The scaled down height of the buildings is $h=500 \mathrm{~mm}$ and the scaled down diameter of the circle inscribed in the plan shape is $100 \mathrm{~mm}$ for all the buildings. The aspect ratio is 1:5 for the principal as well as interfering buildings. The numerical simulation is carried out for the octagonal plan shaped building in the presence of three square plan shaped buildings as shown in Fig. 3 for $0^{\circ}$ wind incidence angle only. The spacing from the principal building to upstream interfering buildings, i.e. $S_{1}=200 \mathrm{~mm}(=0.4 h)$. The spacing between the upstream interfering buildings, i.e. $S_{2}$ is varied. The spacing between the principal and the third interfering building, i.e. $S_{3}$ is also varied.

\section{Results and discussion}

\section{Isolated condition}

In this case the octagonal plan shaped building is subjected to boundary layer wind flow at $0^{\circ}$ wind incidence angle and analysed using $k-\varepsilon$ turbulence model by ANSYS CFX.

\section{Flow pattern}

The flow pattern around the building is shown in Fig. 4.

The key features observed from the flow pattern are summarized below

1. As the plan shape is symmetrical the flow pattern is also symmetrical till the formation of vortices. Thus symmetrical faces will have identical or at least similar pressure distribution.
Fig. 3 Plan view of principal and interfering buildings with direction of wind flow

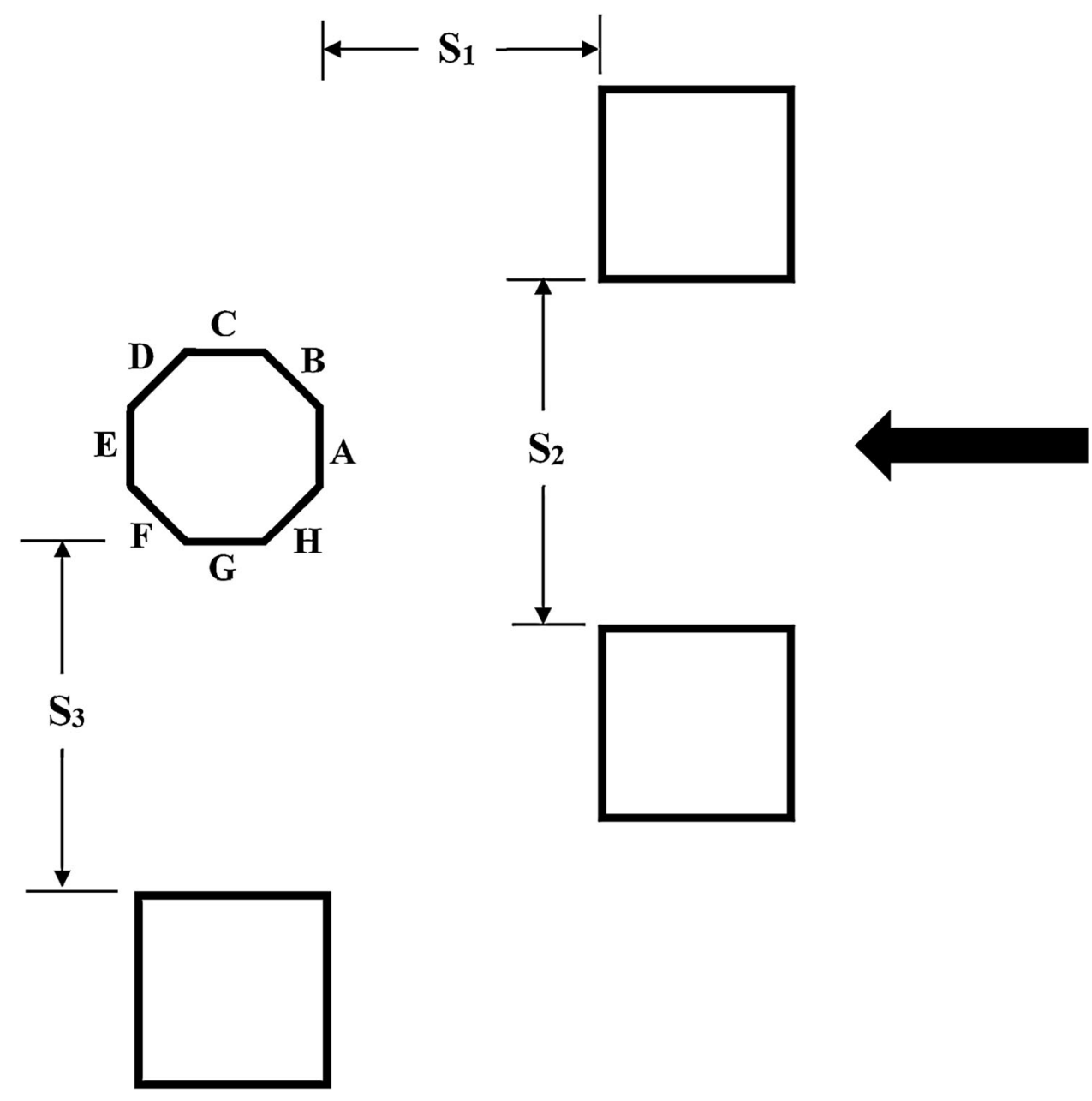


Fig. 4 Plan of flow pattern around model for $0^{\circ}$ wind incidence angle for $k-\varepsilon$ model

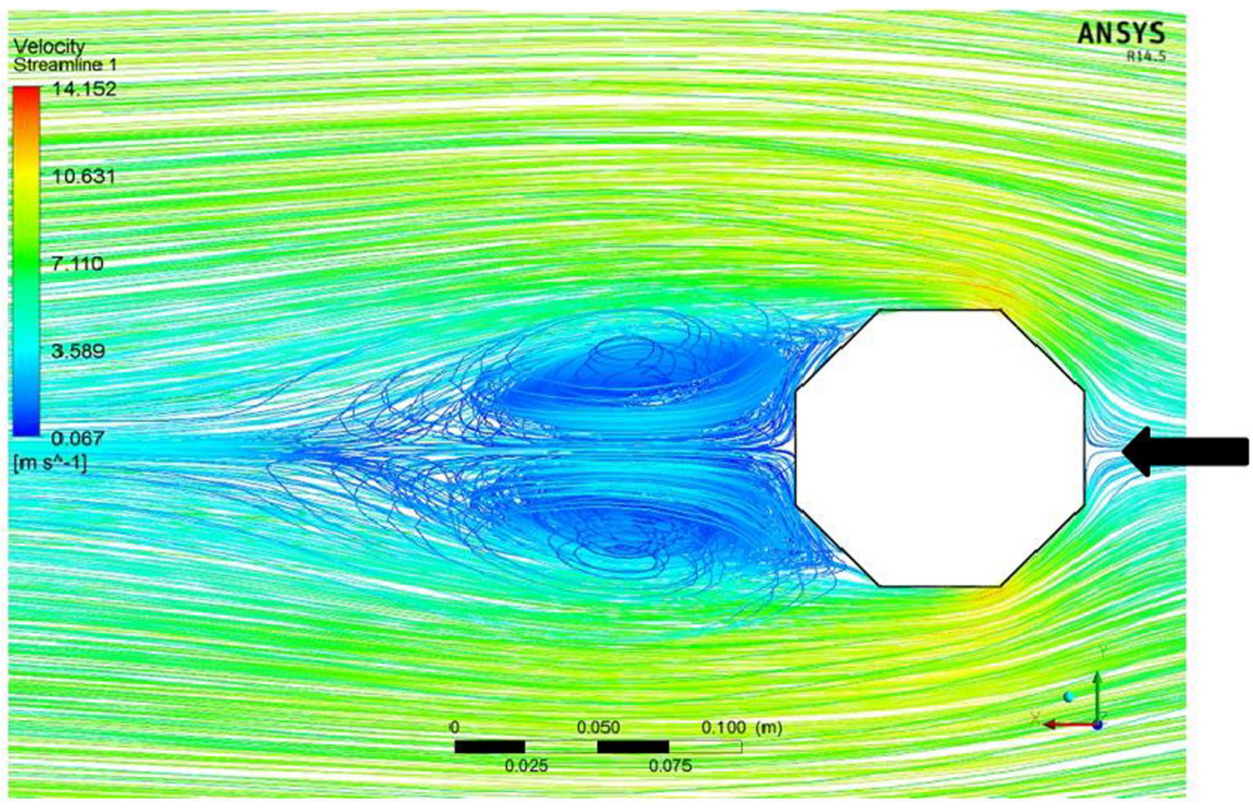

2. The wind flow separates after colliding with the windward face, i.e. face $\mathrm{A}$ so it will have positive pressure with slight negative values near the edges due to flow separation.

3. The inclined windward faces, i.e. faces $\mathrm{B}$ and $\mathrm{H}$ will experience slight positive value of pressure near face $\mathrm{A}$ junction and gradually develops negative pressure away from it.

4. The side faces $\mathrm{C}$ and $\mathrm{G}$ will have negative pressure due to side wash.

5. The back faces, i.e. faces $\mathrm{D}, \mathrm{E}$ and $\mathrm{F}$ will experience negative pressure due to side wash and formation of vortices.

\section{Pressure variation}

The model has a symmetrical plan shape and flow pattern is also symmetrical; so only five faces are sufficient for understanding the behaviour of the model under wind action. Pressure contours of the faces A, B, C, D and E are shown in Fig. 5.

The features of the pressure contours are as follows:

1. Face A experiences mainly positive pressure except near the top edge. Pressure distribution is parabolic in nature due to boundary layer flow and symmetrical about vertical centreline.

2. Face $B$ and $H$ have slightly positive pressure near the junction of face $A$ and negative elsewhere.
3. Faces $\mathrm{C}$ and $\mathrm{G}$ have throughout negative pressure with more negative value towards the leeward side.

4. Faces D and F have lower negative value at bottom and higher value towards top.

5. Face $\mathrm{E}$ has a semi-circular zone of lower negative value and an elliptical zone at the middle.

Face average value of pressure coefficient

\section{Interfering condition}

In this case also the buildings are subjected to a boundary layer wind flow at the wind incidence angle $0^{\circ}$ only. The plan view of the principal octagonal as well as the interfering buildings are shown in Fig. 3. The distance between principal to front interfering buildings $S_{1}=200 \mathrm{~mm}$. The distance between principal and the third interfering building $S_{3}$ varies as $200 \mathrm{~mm}(=0.4 h), 300 \mathrm{~mm}(=0.6 h)$ and $500 \mathrm{~mm}(=h)$. The distance between front interfering buildings varies as $S_{2}=200 \mathrm{~mm}(=0.4 h), 500 \mathrm{~mm}(=h), 1000 \mathrm{~mm}(=2 h)$.

\section{Flow pattern}

The wind flow pattern for different interference conditions will be different. Wind flow pattern will change as distances between principal to interfering or between interfering buildings change. In Fig. 6 the flow pattern for a typical case where $S_{1}=0.4 h, S_{2}=0.4 h$ and $S_{3}=0.4 h$ is depicted. 
Fig. 5 Pressure contour on different faces of Octagonal plan shaped building for $0^{\circ}$ wind angle by $k-\varepsilon$ method
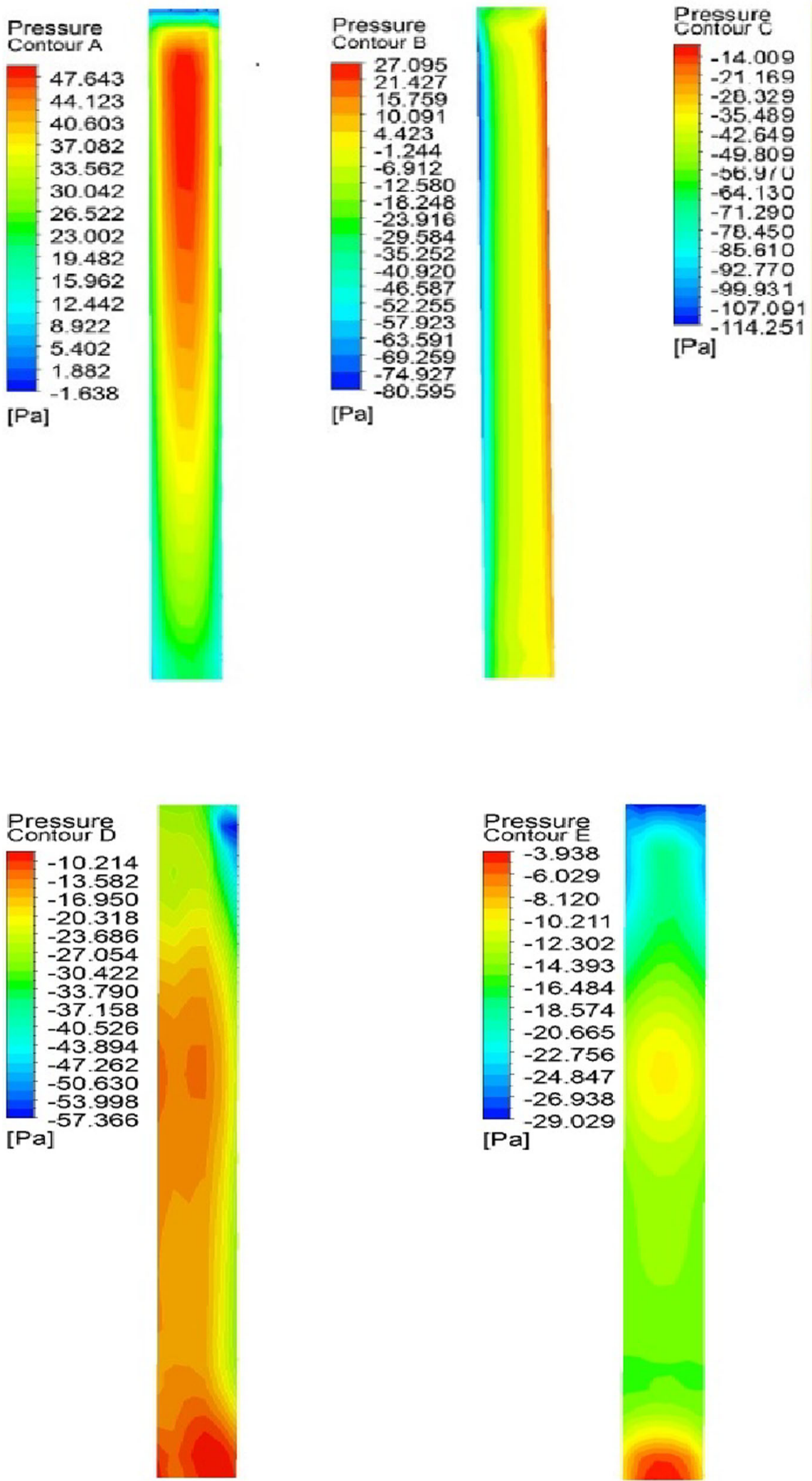
Fig. 6 Plan of flow pattern around building setup for $S_{1}=0.4 h, S_{3}=0.4 h$

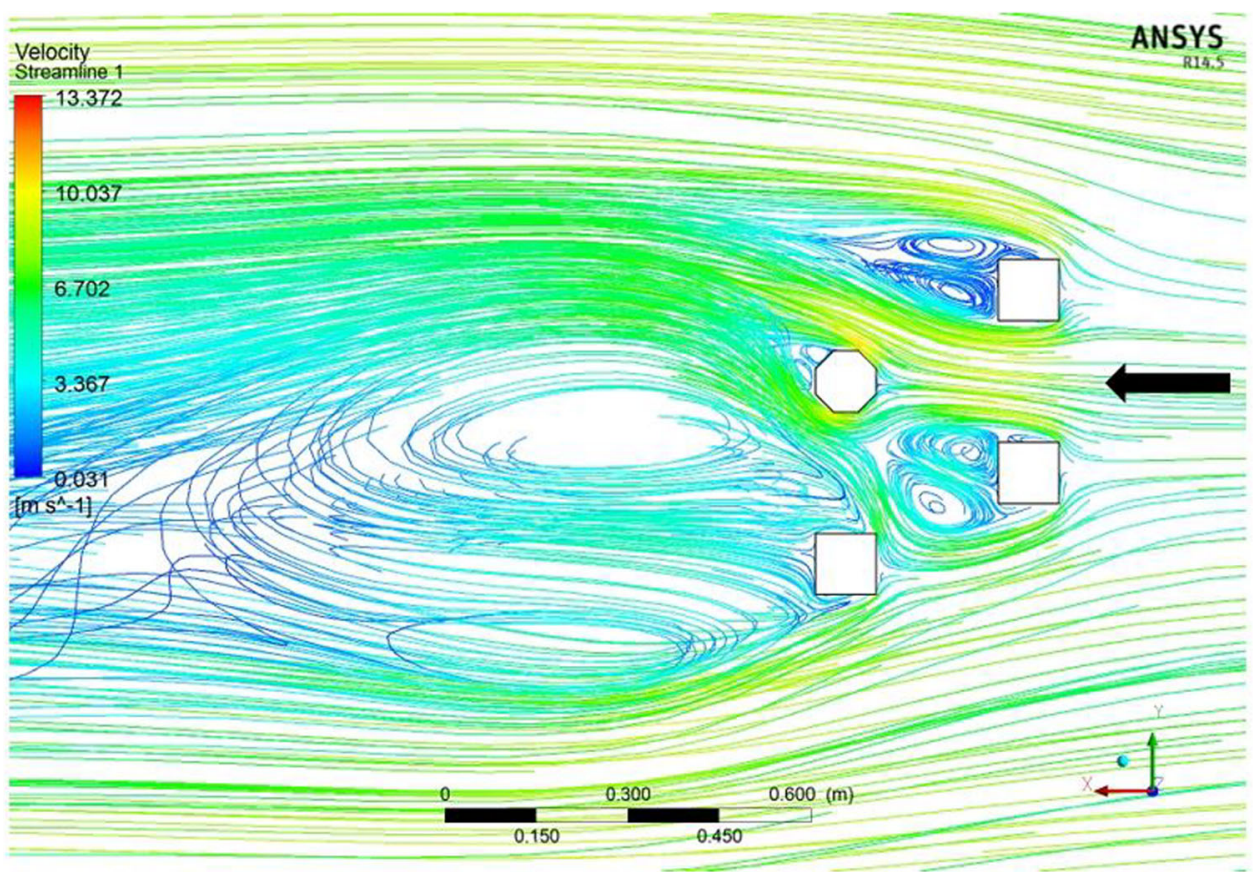

The features observed are as follows:

1. Unsymmetrical vortices are formed in the leeward side of the principal building due to interference effects of the other interfering buildings.

2. Pressure in the windward face is almost same. Maybe due to small distance between principal and front buildings is very so less that channelling effect of the front interfering buildings does not affect the principal building.

3. Faces $\mathrm{B}, \mathrm{C}, \mathrm{D}, \mathrm{E}$ and $\mathrm{F}$ have higher magnitude of pressure due to both channelling effect and flow separation.

4. Surprisingly faces $\mathrm{F}, \mathrm{G}$ and $\mathrm{H}$ have lower pressure probably due to Shielding effect of the third interfering building.

\section{Interference factor contour}

Interference factor for selected points is given by,

$\mathrm{IF}_{\mathrm{p}}=\frac{\text { Pressure for selected point in interfering condition }}{\text { Pressure for selected point in isolated condition }}$

Interference factor (IF) thus found can be used to plot interference factor contour for each face. Interference factor for above mentioned case for faces A, C, E, F and H are shown in Fig. 7.

The key features observed from the IF contours are as follows:
1. There is no interference in face A except for the top portion of the face.

2. Faces $\mathrm{C}$ and $\mathrm{F}$ has interference throughout the surfaces.

3. Face $\mathrm{E}$ seems to have negligible interference slightly below the horizontal centreline of the face.

4. Face $\mathrm{H}$ also has negligible interference except for the region slightly below the top portion.

Interference factor contour can be a pretty useful tool for depicting the local interference of a building face.

Case I: $S_{1}=0.4 \mathrm{~h}, S_{3}=0.4 \mathrm{~h}$

In this case $S_{1}$ and $S_{3}$ remains constant and $S_{2}$ varies as $0.4 h, h$ and $2 h$. The comparison of pressure coefficient $\left(C_{\mathrm{p}}\right)$ on all faces, i.e. A, B, C, D, E, F, G and $\mathrm{H}$ along the vertical centreline depicting the variation as the distance $S_{2}$ varies is shown in Fig. 8.

The inferences drawn from the plot of pressure coefficient along vertical centreline are as follows:

1. Face A does not experience much variation from each other or the isolated case. The front interfering buildings are too close to the principal building so the channelling effect does not affect the front face.

2. In case of face B the magnitude of $C_{\mathrm{p}}$ is higher when $S_{2}=0.4 h$ than the other cases. The reason is the combined effect of channelling effect by the front interfering buildings and shielding effect of the third interfering building present at the other side which can 
Fig. 7 Contours of interference factors for; $\mathbf{a}$ face $\mathrm{A}, \mathbf{b}$ face $\mathrm{C}$, c face $E, \mathbf{d}$ face $F$, e face $H$

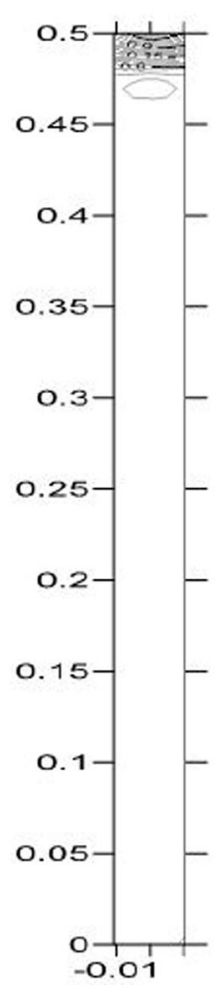

A

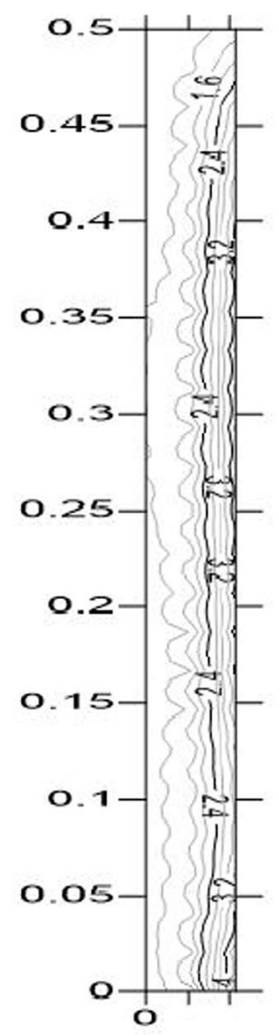

D

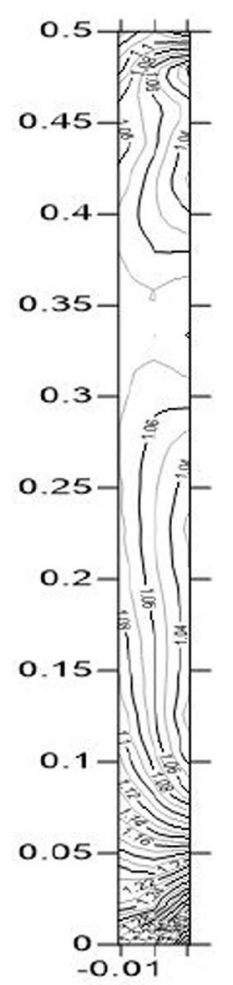

B

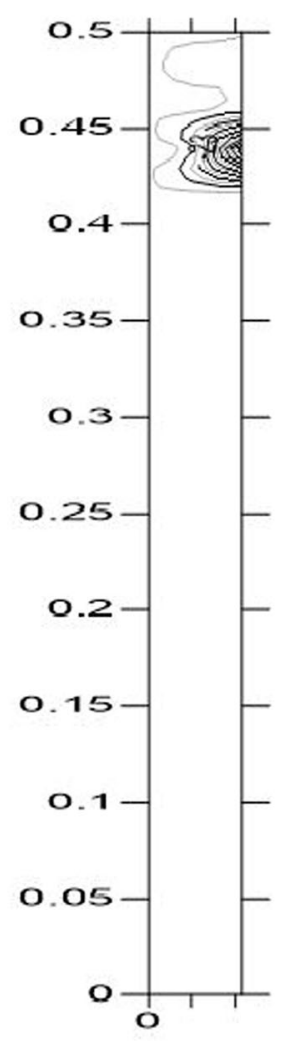

$\mathbf{E}$

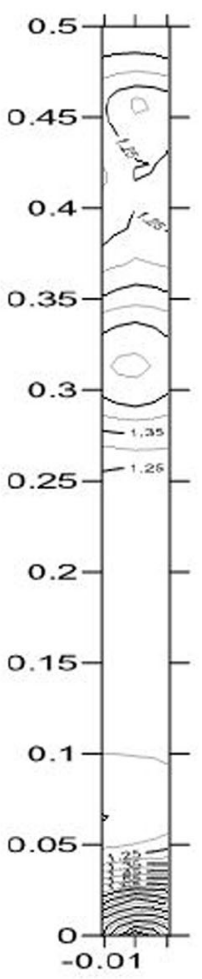

C 


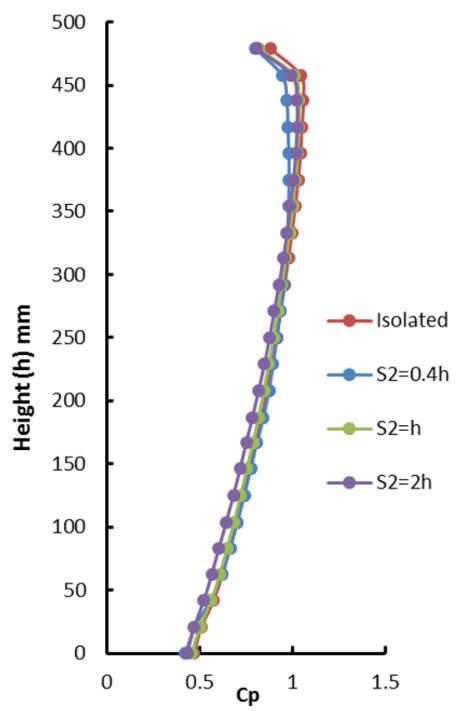

Face A

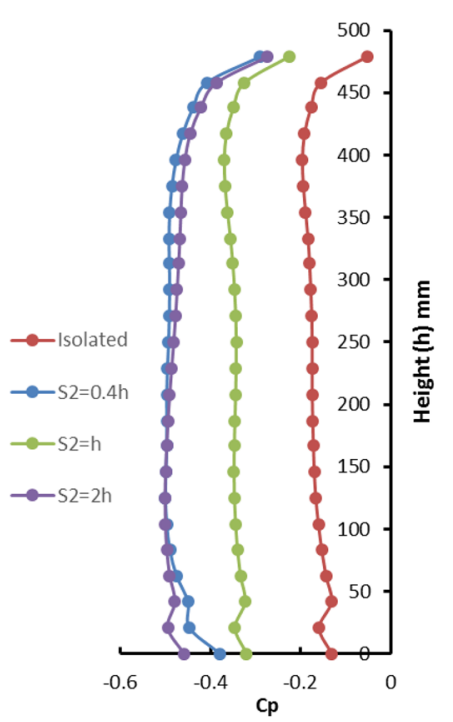

Face B

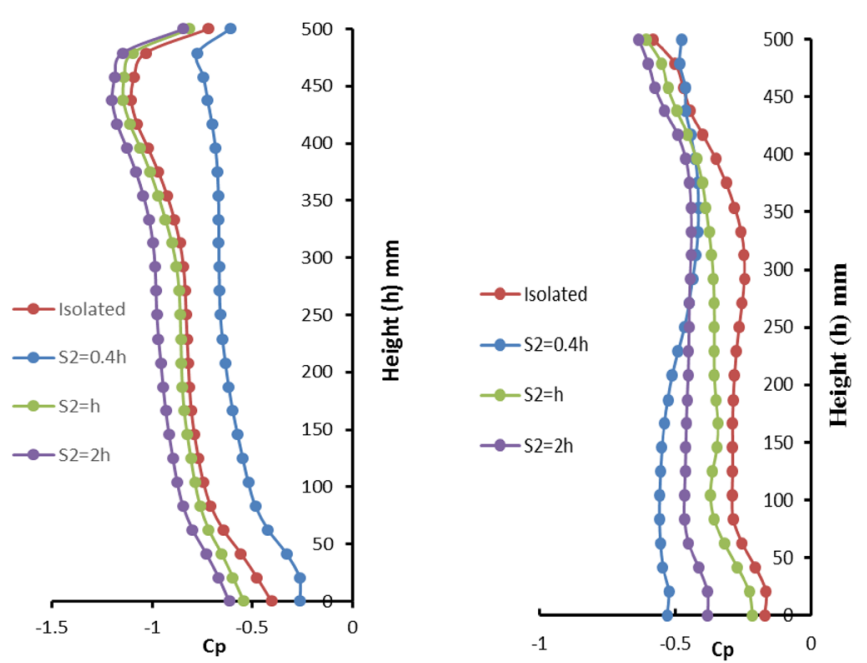

Face C

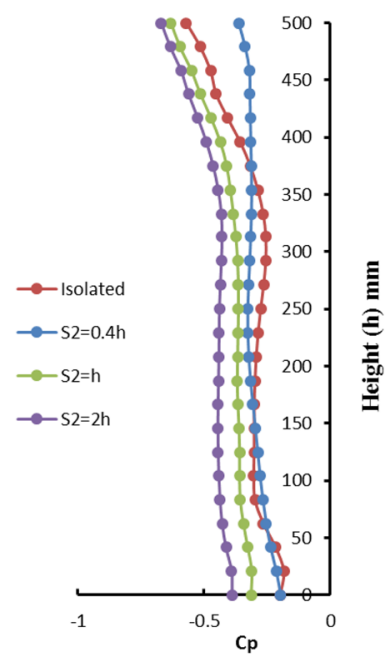

Face D
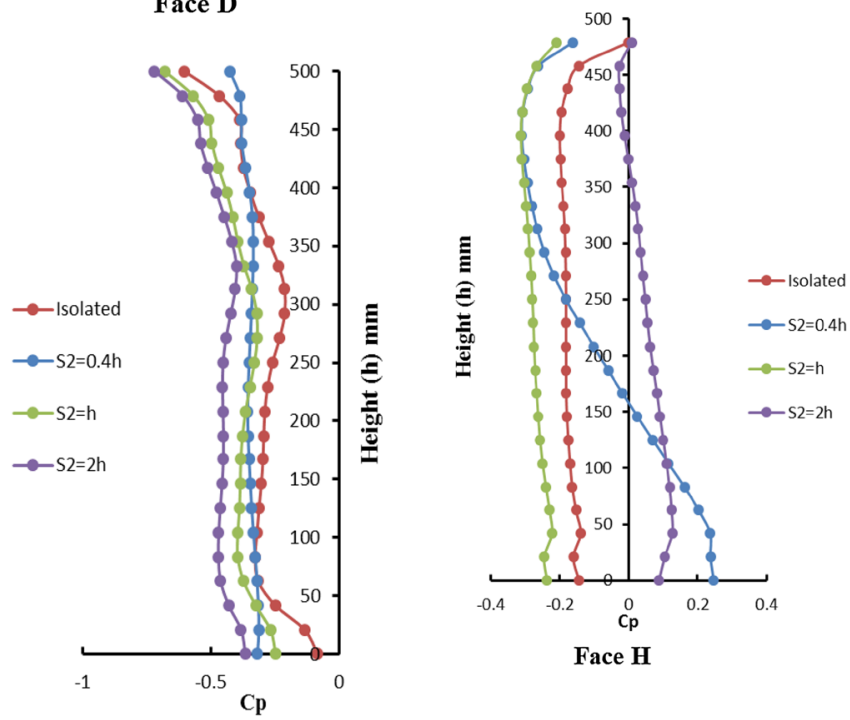

Face E

Fig. 8 Comparison of variation of pressure coefficient along vertical centreline if $S_{3}=0.4 h$ for different faces 
be proved by the higher velocity of wind in the zone near the faces B, C and D.

3. For the faces $\mathrm{C}, \mathrm{D}, \mathrm{E}$ and $\mathrm{G}$ the general trend is as $S_{2}$ increases the magnitude of $C_{\mathrm{p}}$ also increases.

4. The face $\mathrm{F}$ also behaves like the face $\mathrm{B}$, i.e. magnitude of $C_{\mathrm{p}}$ is much higher at $S_{2}=0.4 \mathrm{H}$ than the other cases.

5. The behaviour of face $\mathrm{H}$ is completely arbitrary except for the case $S_{2}=2 \mathrm{H}$ where the $C_{\mathrm{p}}$ have positive values deviating from the usual behaviour. The reason maybe that the channelling effect of the upstream interfering buildings becomes negligible and the shielding effect of the third interfering building becomes dominant.

It can be observed that the behaviour is pretty haphazard except for some cases as described previously.

\section{Case II: $S_{1}=0.4 h, S_{3}=0.6 h$}

In this case $S_{1}$ and $S_{3}$ remains constant and $S_{2}$ varies as $0.4 \mathrm{H}, \mathrm{H}$ and $2 \mathrm{H}$. The comparison of pressure coefficient $\left(C_{\mathrm{p}}\right)$ on all faces, i.e. A, B, C, D, E, F, G and $\mathrm{H}$ along the vertical centreline depicting the variation as the distance $S_{2}$ varies is shown in Fig. 9.

The key features observed from the plot of pressure coefficient along vertical centreline are as follows:

1. Like the previous case in this case also the variation in the plot of $C_{\mathrm{p}}$ along vertical centreline for different cases is not so prominent due to the similar reason.

2. In this case face B experiences lesser pressure as $S_{2}$ increases. The cause is the decrease in velocity when compared to the previous case due to the increase in the distance $S_{3}$.

3. For the faces $\mathrm{C}, \mathrm{D}, \mathrm{E}, \mathrm{F}$ and $\mathrm{G}$ the magnitude of pressure coefficient increases when the distance $S_{2}$ increases from $0.4 h$ to $0.6 h$ which is due to the decrease of channelling effect caused by the upstream interfering buildings. The pressure coefficient again decreases when $S_{2}=h$ probably due to decrease in interference by the upstream buildings on the principal building.

4. In this case face $\mathrm{H}$ exhibits steady decrease in pressure coefficient due to the shielding effect of the third interfering building at the side. The magnitude of pressure coefficient is even lower than the value at isolated condition.

In this case it can be seen that the variation of pressure coefficient is pretty systematic when compared to the previous case.

Case III: $S_{1}=0.4 h, S_{3}=h$

In this case $S_{1}$ and $S_{3}$ remains constant and $S_{2}$ varies as $0.4 h, h$ and $2 h$. The comparison of pressure coefficient $\left(C_{\mathrm{p}}\right)$ on all faces, i.e. A, B, C, D, E, F, G and $\mathrm{H}$ along the vertical centreline depicting the variation as the distance $S_{2}$ varies is shown in Fig. 10.

The key features observed from the plot of pressure coefficient along vertical centreline are as follows:

1. Similar to the previous two cases the plot of pressure coefficient along height does not vary much when $S_{2}$ increases.

2. Face B experiences less pressure coefficient as the distance $S_{2}$ increases. The magnitude of pressure coefficient is lesser than that in the previous case. The cause is the velocity of wind in that region decreases as compared to the previous case due increase in the distance $S_{3}$, i.e. distance between principal building and the third interfering building.

3. For the faces $C, D, E, F$ and $G$ the magnitude of pressure coefficient increases as the distance $S_{2}$ increases. In this case the magnitudes of pressure coefficients at $S_{2}=0.6 h$ and $S_{2}=h$ are almost same for these faces.

4. For face $\mathrm{H}$ also similar trend is observed, i.e. magnitude of pressure coefficient decreases with the increase of $S_{2}$. But here the magnitudes of pressure coefficients are greater than that of the isolated case. The behaviour deviates from the previous case from which it can be concluded that when the distance from the third building from the principal building, i.e. $S_{3}=h$, the shielding effect of the third building reduces substantially.

This case is pretty different from the previous two cases as the effect of third building on the principal building is reduced.

\section{Interference factor}

Interference effects are presented in the form of non-dimensional interference factors (IF) that represent the aerodynamic forces on an octagonal plan shaped principal building with interference from adjacent three square plan shaped buildings. IF is given by the following formula

I.F. $=\frac{\text { Mean pressure for a face in interfering condition }}{\text { Mean pressure for a face in isolated condition }}$

Here is a guideline for wind load modifications in planning and designing an octagonal plan shaped building surrounded by some square plan shaped buildings. If $C_{\mathrm{p}}$ be the face average value of pressure coefficient for a particular face in isolated condition then the same for any particular interfering condition is given by

$C_{\mathrm{p} \text {,interfering }}=$ I.F. $\times C_{\mathrm{p} \text {,isolated }}$ 


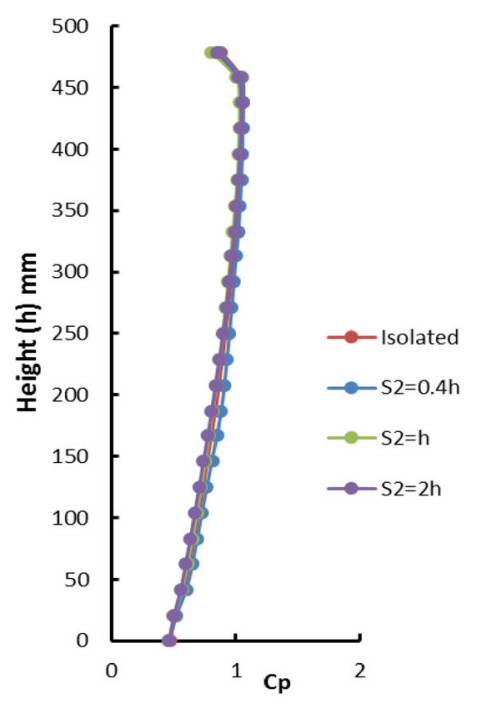

Face A

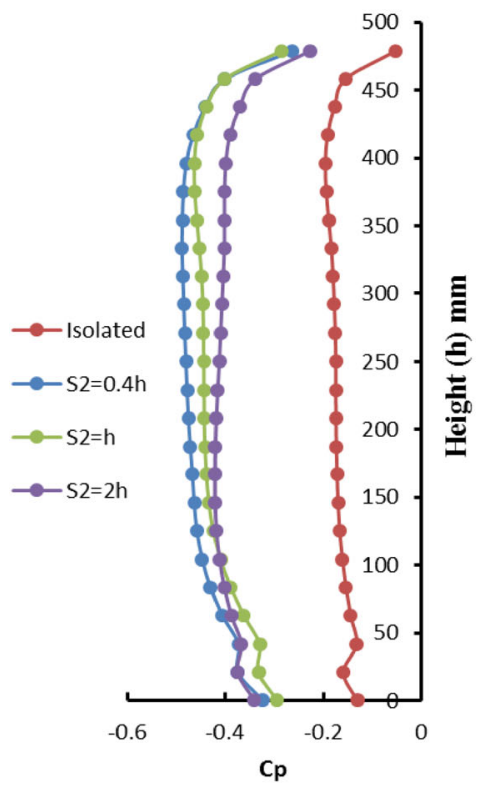

Face B

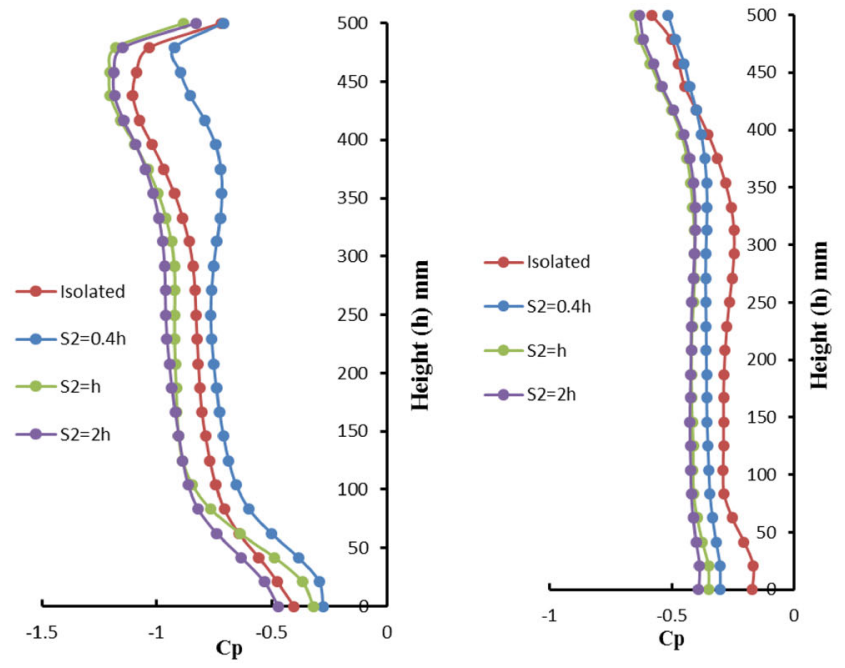

Face $F$

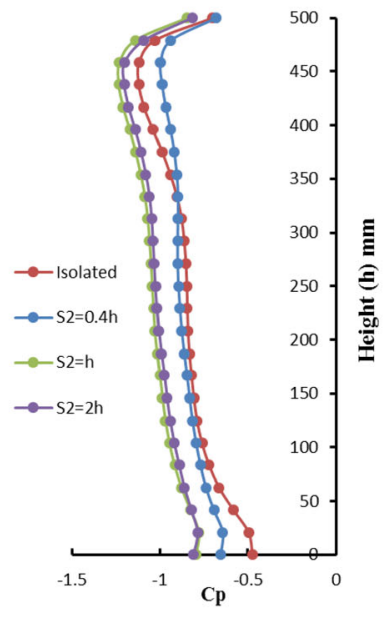

Face G

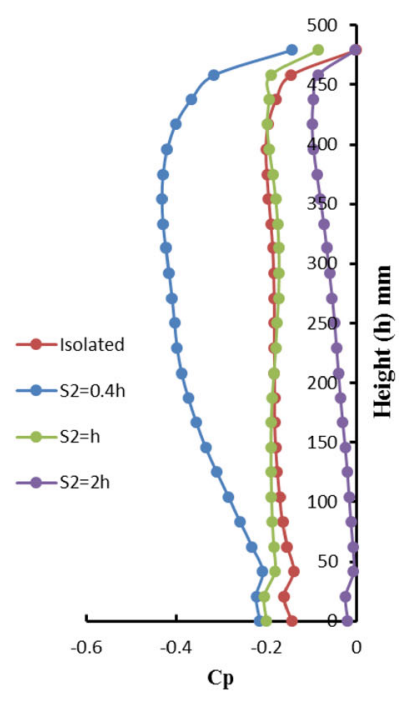

Face $\mathbf{H}$

Face E

Fig. 9 Comparison of variation of pressure coefficient along vertical centreline if $S_{3}=0.6 h$ for different faces 


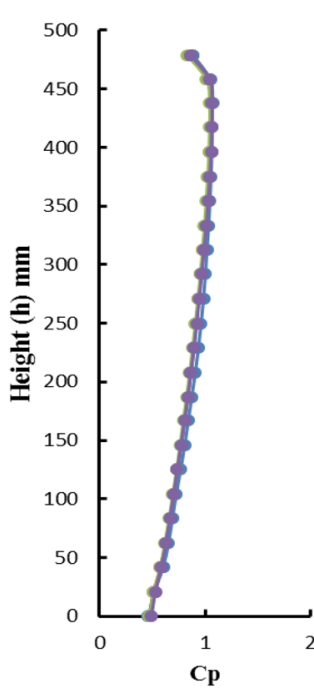

Face A

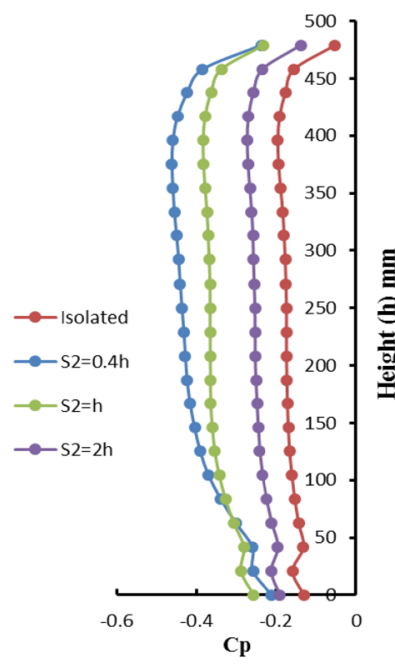

Face B

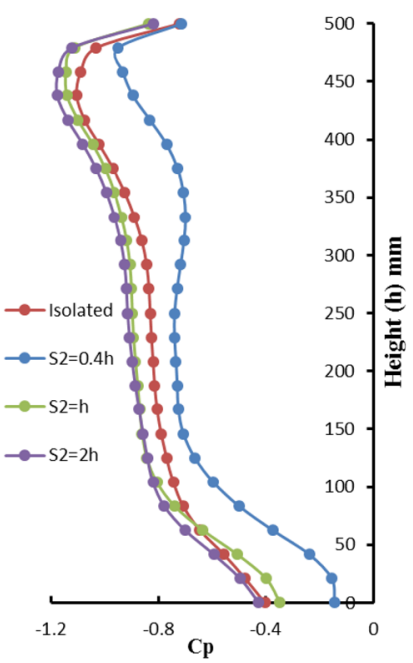

Face C

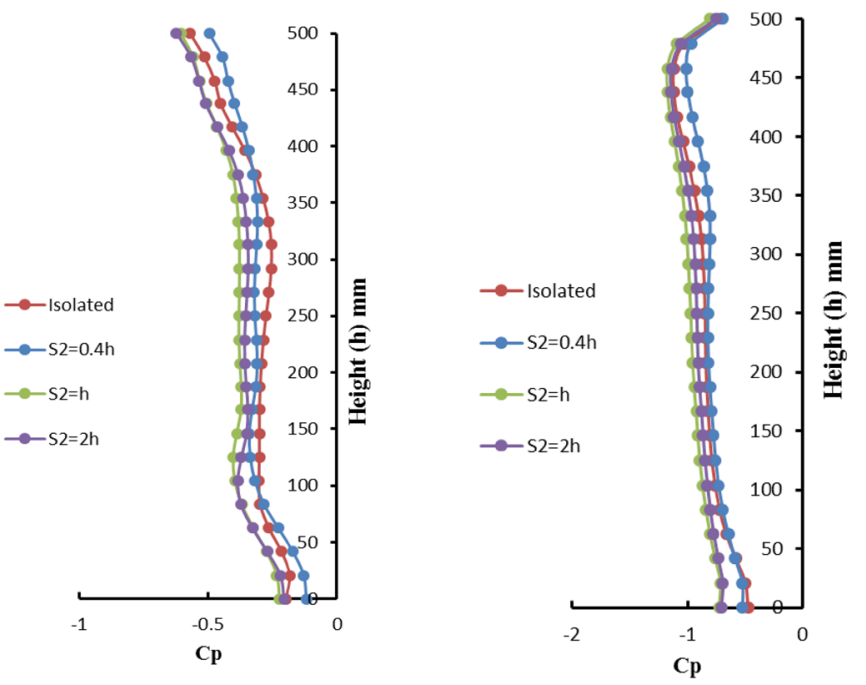

Face G

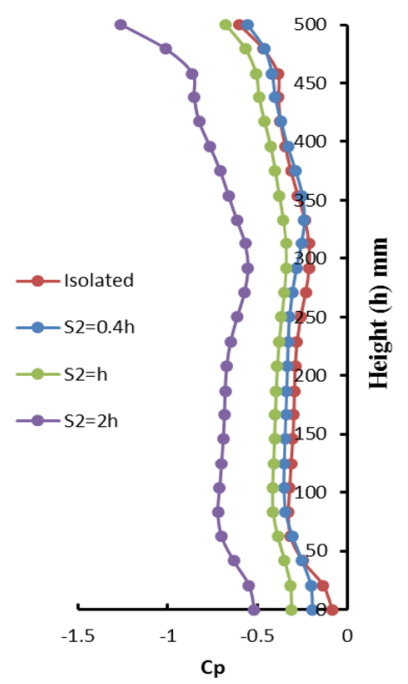

Face $\mathbf{E}$

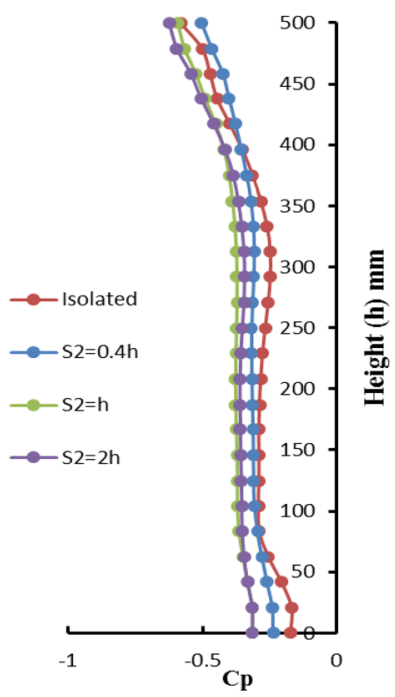

Face $\mathbf{F}$

Fig. 10 Comparison of variation of pressure coefficient along vertical centreline if $S_{3}=h$ for different faces 
Table 2 Face average values of pressure coefficients for $0^{\circ}$ wind incidence angle

\begin{tabular}{ll}
\hline Location & $\begin{array}{l}\text { Face average values } \\
\text { of pressure coefficient }\end{array}$ \\
\hline Face A & 0.78 \\
Face B & -0.29 \\
Face C & -0.94 \\
Face D & -0.37 \\
Face E & -0.58 \\
Face F & -0.36 \\
Face G & -0.92 \\
Face H & -0.29 \\
\hline
\end{tabular}

where IF is the interference factor of that face in that particular condition. $C_{\mathrm{p} \text {,isolated }}$ can be found from Table 2 .

The interference factor for the previously mentioned cases are tabulated in Table 3. The interference factor for the intermediate cases can be calculated by linear interpolation.

\section{Conclusion}

The study carried out till now has shown regular plan shape buildings experiences symmetrical pressure distribution for $0^{\circ}$ wind incidence angle in isolated condition. The interference effect on different faces should also be kept in mind while calculating the wind load on buildings or any other important structures. The significant outcomes of this present study on the "octagonal" plan shaped tall building can be summarized as follows:

1. The octagonal plan shaped building experiences symmetrical pressure distribution in isolated condition.

2. In the interfering condition the pressure distribution cannot be predicted accurately. It can be seen from
Table 3 that no particular pattern in IF can be seen with the change in distances between the buildings.

3. When the distance between the principal building and the third interfering building is $200 \mathrm{~mm}$ (i.e. $\left.S_{3}=0.4 h\right)$ the behaviour cannot be predicted with the change in $S_{2}$ with some exception. But the channelling effect of the two upstream buildings and the shielding effect of the third interfering building is evident.

4. In the case II where the distance between the principal building and the third interfering building is $300 \mathrm{~mm}$ (i.e. $S_{3}=0.6 h$ ) the behaviour of the faces due to interference becomes slightly more systematic than the previous case. As the distance between two upstream buildings increase the shielding effect of the third interfering building becomes more prominent.

5. In the case III where the distance between the principal building and the third interfering building is $500 \mathrm{~mm}$ (i.e. $S_{3}=h$ ) the behaviour of the faces due to interference remains similar to the previous case. The difference is that $S_{3}$ is increased so the channelling effect of the upstream interfering buildings become prevalent and the shielding effect due to the third interfering building decreases.

6. From Table 3, we can see that in many occasions the values of the interference factor is greater than unity, i.e. the coefficient of pressure in that particular interfering case is greater than that in isolated case. This proves that the presence of the interfering buildings does not always contribute to the decrease of wind load on the principal building.

7. The pressure coefficients for the interfering cases can be easily found out from expression (9) if the same for the isolated case and the corresponding IF for the interfering case is known for the octagonal plan shaped building of the similar aspect ratio.
Table 3 Mean interference factor for each faces of principal octagonal building for different cases

\begin{tabular}{|c|c|c|c|c|c|c|c|c|c|c|}
\hline \multirow[t]{2}{*}{$S_{1}(\mathrm{~mm})$} & \multirow[t]{2}{*}{$S_{3}(\mathrm{~mm})$} & \multirow[t]{2}{*}{$S_{2}(\mathrm{~mm})$} & \multicolumn{8}{|c|}{ Interference factor for faces } \\
\hline & & & A & B & $\mathrm{C}$ & $\mathrm{D}$ & $\mathrm{E}$ & $\mathrm{F}$ & G & $\mathrm{H}$ \\
\hline \multirow[t]{9}{*}{$0.4 h$} & \multirow[t]{3}{*}{$0.4 h$} & $0.4 h$ & 0.95 & 1.86 & 1.08 & 1.10 & 1.09 & 1.64 & 0.84 & 0.54 \\
\hline & & $h$ & 0.95 & 1.59 & 1.08 & 1.14 & 1.28 & 1.17 & 1.11 & 0.42 \\
\hline & & $2 h$ & 0.99 & 2.06 & 1.17 & 1.32 & 1.50 & 1.59 & 1.15 & 0.38 \\
\hline & \multirow[t]{3}{*}{$0.6 h$} & $0.4 h$ & 0.96 & 1.80 & 0.92 & 0.95 & 1.18 & 1.16 & 1.03 & 1.46 \\
\hline & & $h$ & 0.95 & 1.85 & 1.11 & 1.23 & 1.46 & 1.38 & 1.19 & 1.12 \\
\hline & & $2 h$ & 0.99 & 1.03 & 1.22 & 1.30 & 1.24 & 1.20 & 1.15 & 0.77 \\
\hline & \multirow[t]{3}{*}{$h$} & $0.4 h$ & 0.95 & 1.61 & 0.88 & 0.87 & 1.05 & 0.98 & 0.99 & 1.77 \\
\hline & & $\mathrm{H}$ & 0.96 & 1.61 & 1.07 & 1.13 & 1.31 & 1.23 & 1.13 & 1.30 \\
\hline & & $2 h$ & 0.99 & 1.25 & 1.07 & 1.15 & 1.27 & 1.20 & 1.10 & 1.22 \\
\hline
\end{tabular}


Open Access This article is distributed under the terms of the Creative Commons Attribution 4.0 International License (http://crea tivecommons.org/licenses/by/4.0/), which permits unrestricted use, distribution, and reproduction in any medium, provided you give appropriate credit to the original author(s) and the source, provide a link to the Creative Commons license, and indicate if changes were made.

\section{References}

Agarwal N, Mittal AK, Gupta VK (2012) Along-wind interference effects on tall buildings. In: National Conference on Wind Engineering, pp 193-204

Cheng CM, Lu PC, Tsai MS (2002) Acrosswind aerodynamic damping of isolated square shaped buildings. J Wind Eng Ind Aerodyn 90:1743-1756

Franke J, Hirsch C, Jensen A, Krüs H, Schatzmann M, Westbury P, Miles S, Wisse J, Wright NG (2004) Recommendations on the use of CFD in Wind Engineering. In: COST Action C14: Impact of Wind and Storm on City Life and Built Environment, von Karman Institute for Fluid Dynamics

IS 875 (Part 3)-1987 Indian Standard code of practice for design loads (other than earthquake) for building and structures, bureau of indian standard, New Delhi
Kim YM, You KP (2002) Dynamic responses of a tapered tall building to wind loads. J Wind Eng Ind Aerodyn 90:1771-1782

Lakshmanan N, Arunachalam S, Rajan SS, Babu GR, Shanmugasundaram J (2002) Correlations of aerodynamic pressures for prediction of acrosswind response of structures. J Wind Eng Ind Aerodyn 90:941-960

Lam KM, Leung MYH, Zhao JG (2008) Interference effects on wind loading of a row of closely spaced tall buildings. J Wind Eng Ind Aerodyn 96:562-583

Tanaka H, Tamura Y, Ohtake K, Nakai M, Kim YC (2012) Experimental investigation of aerodynamic forces and wind pressures acting on tall buildings with various unconventional configurations. J Wind Eng Ind Aerodyn 107-108:179-191

Tang UF, Kwok KCS (2004) Interference excitation mechanisms on a 3DOF aeroelastic CAARC building model. J Wind Eng Ind Aerodyn 92:1299-1314

Thepmongkorna S, Wood GS, Kwok KCS (2002) Interference effects on wind-induced coupled motion of a tall building. J Wind Eng Ind Aerodyn 90:1807-1815

Xie ZN, Gu M (2004) Mean interference effects among tall buildings. Int J Eng Struct 26:1173-1183 